\title{
A Genetic Analysis for Patients with Pulmonary Arterial Hypertension
}

\author{
Yu Yoshida, Keiko Uchida, Kazuki Kodo, Yoshiyuki Furutani, \\ Toshio Nakanishi, and Hiroyuki Yamagishi
}

\author{
Keywords \\ T-box $\cdot$ TBX4 $\cdot$ Pulmonary hypertension $\cdot$ Genetic analysis
}

Pulmonary arterial hypertension (PAH) is a lethal disease [1]. Although mutations in $B M P R 2$ and other genes have been reported, the genetic causes in large numbers of patients, especially with sporadic PAH, remain unknown. In 2013, KerstjensFrederikse et al. first reported TBX4 mutations in patients with PAH [2]. TBX4 is an essential transcription factor for the development of the hindlimbs and lungs [3]. In European countries, the frequency of TBX4 mutation was reported as $2.4-4.1 \%$ in adult-onset PAH [2, 4] and as 7.5-30\% in child-onset PAH [2, 5] (Fig. 27.1). However, its frequency in Asian patients with PAH has yet to be studied.

In our genetic analysis for patients with $\mathrm{PAH}$, at least nine sequence variants in exons and six sequence variants in flanking introns of TBX4 were found. The allele frequencies of variants in the Japanese population are under investigation. The detected variants will be validated using the following web databases: UCSC genome browser (https://genome-asia.ucsc.edu), Ensembl (http://www.ensembl. org), PolyPhen-2 (http://genetics.bwh.harvard.edu/pph2), SIFT (http://sift.jcvi.org), Human Splicing Finder (http://umd.be/HSF3), and Protein Data Bank Japan (https://

\footnotetext{
Y. Yoshida $\cdot$ K. Uchida $\cdot$ K. Kodo

Department of Pediatrics, Keio University School of Medicine, Shinjuku, Tokyo, Japan

Y. Furutani · T. Nakanishi

Department of Pediatric Cardiology, Tokyo Women's Medical University, Tokyo, Japan e-mail: nakanishi.toshio@twmu.ac.jp

H. Yamagishi $(\square)$

Division of Pediatric Cardiology, Department of Pediatrics,

Keio University School of Medicine, Tokyo, Japan

e-mail: hyamag@keio.jp
} 


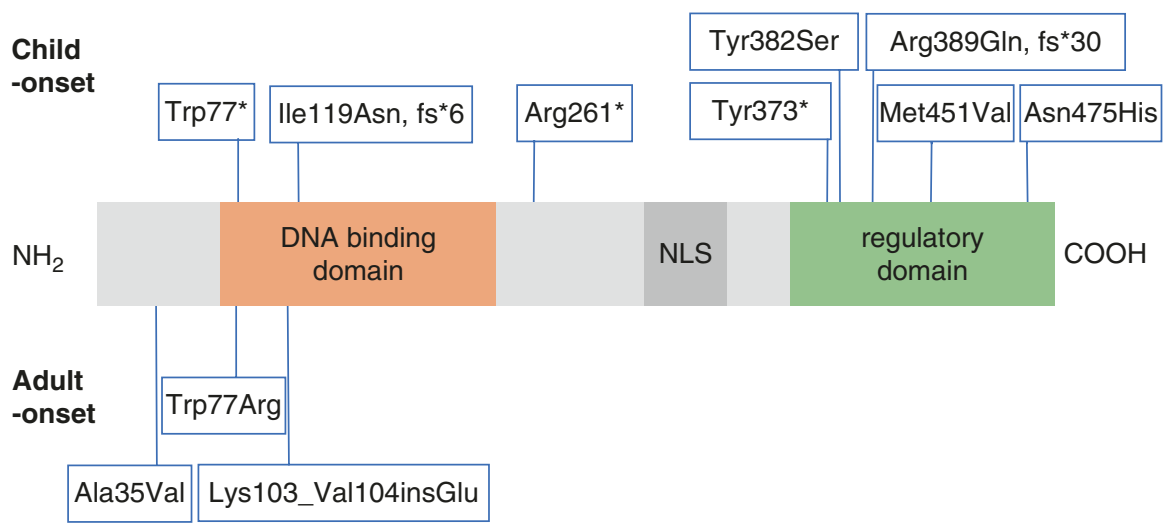

Fig. 27.1 Summary of the position of the previously reported variants in TBX4. Upper labels indicate variants with child-onset $\mathrm{PAH}$; lower labels indicate variants with adult-onset PAH. $N L S$ nuclear localization signal

pdbj.org) for their functional significance. We are further attempting to establish the experimental system of functional analysis for the identified variants of $T B X 4$ using cell culture with luciferase, immunoprecipitation, and immunohistochemistry assays in order to elucidate the molecular mechanism underlying $\mathrm{PAH}$ resulting from $T B X 4$ mutations.

This study suggests that TBX4 may be a prevalent genetic cause of PAH not only in Caucasians but also within Japanese/Asian populations. Our ongoing studies would soon reveal the functional relevance and genotype-phenotype correlations in patients with PAH associated with $T B X 4$ mutations.

\section{References}

1. Chin K, Torres F, Rubin LJ. Idiopathic and heritable pulmonary hypertension: introduction to pathophysiology and clinical aspects. In: Peacock AJ, Naeije R, Rubin LJ, editors. Pulmonary circulation: diseases and their treatment. 3rd ed. London: Hodder Arnold; 2012. p. 207-11.

2. Kerstjens-Frederikse WS, Bongers EM, Roofthooft MT, et al. TBX4 mutations (small patella syndrome) are associated with childhood-onset pulmonary arterial hypertension. J Med Genet. 2013;50:500-6.

3. Papaioannou VE. The T-box gene family: emerging roles in development, stem cells and cancer. Development. 2014;141:3819-33.

4. Navas P, Tenorio J, Quezada CA, et al. Molecular analysis of BMPR2, TBX4, and KCNK3 and genotype-phenotype correlations in Spanish patients and families with idiopathic and hereditary pulmonary arterial hypertension. Rev Esp Cardiol. 2016;69:1011-9.

5. Levy M, Eyries M, Szezepanski I, et al. Genetic analyses in a cohort of children with pulmonary hypertension. Eur Respir J. 2016;48:1118-26. 
Open Access This chapter is licensed under the terms of the Creative Commons Attribution 4.0 International License (http://creativecommons.org/licenses/by/4.0/), which permits use, sharing, adaptation, distribution and reproduction in any medium or format, as long as you give appropriate credit to the original author(s) and the source, provide a link to the Creative Commons license and indicate if changes were made.

The images or other third party material in this chapter are included in the chapter's Creative Commons license, unless indicated otherwise in a credit line to the material. If material is not included in the chapter's Creative Commons license and your intended use is not permitted by statutory regulation or exceeds the permitted use, you will need to obtain permission directly from the copyright holder. 